\title{
Cutting corners
}

\author{
Donald D. Glower, MD
}

See related article on pages 1296-300.

Asai and colleagues ${ }^{1}$ present the results of mitral valve repair with quadrangular resection versus butterfly resection in 76 consecutive patients with posterior leaflet prolapse. The authors conclude that butterfly resection provides acceptable early and medium-term results. Although this is a small, retrospective, and nonrandomized series, the degree of echocardiographic follow-up at 1 to 2 years is good. The main contribution of this article is to provide early echocardiographic follow-up of the butterfly repair technique.

Many modifications have been described for the standard quadrangular resection and sliding leaflet plasty first reported by Perier and colleagues ${ }^{2}$ for P2 posterior leaflet mitral valve prolapse. ${ }^{3,4}$ The technique described by Asai and colleagues ${ }^{1}$ is attractive because of its simplicity and geometric sensibility (Figure 1). Essentially, this is the original sliding leaflet plasty with removal of the leading edge corners on the remaining P1 and P3 segments and retaining 2 wedges of tissue at the base of the P1 and P3 segments. The effect is to shorten the length of the posterior leaflet leading edge and to bolster the amount of leaflet tissue at the base of the new P2. An advantage might be to minimize residual excessive length of the new $\mathrm{P} 2$ leading edge, thereby preventing buckling or folding of the new P2 and potentially minimizing the tendency toward systolic anterior motion. In addition, the retained tissue at the base of $\mathrm{P} 2$ should improve the length of the coaptation zone with the anterior leaflet and should drop the angle of $\mathrm{P} 2$ to more nearly perpendicular to the valve plane. The technique does not pose many obvious disadvantages, as long as the principles of the original sliding leaflet palsy are followed, namely, eliminating gaps of more than $4 \mathrm{~mm}$ between good chords and keeping the height of the posterior leaflet 10 to $15 \mathrm{~mm}$.

The authors demonstrate comparable short-term results with this technique relative to historical controls. Although the technique appears visually and aesthetically superior to the standard technique, the authors are not able to provide

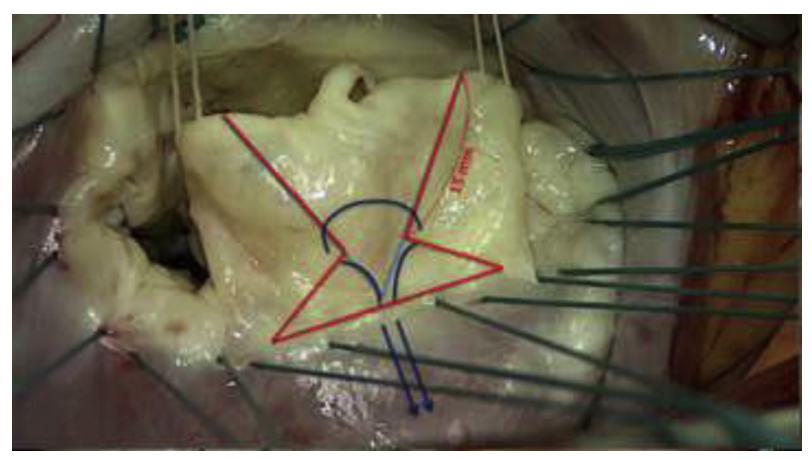

FIGURE 1. The butterfly resection technique for posterior mitral prolapse as described by Asai and colleagues.

any demonstrable superiority that could be quantified. It is in fact possible that many surgeons subconsciously perform the butterfly technique when performing a sliding plasty by performing more triangular than quadrangular resection of the P2 segment.

This study demonstrates the cosmetic/plastic surgical nature of mitral valve repair. The bottom line is obtaining a functioning and durable result by whatever technique. In fact, many techniques have been described to eliminate the need for leaflet resection altogether in many cases. ${ }^{5}$ The butterfly technique described by Asai and colleagues ${ }^{1}$ might be a useful modification to consider to be incorporated consciously or subconsciously to cut corners during mitral valve repair.

\section{References}

1. Asai T, Kinoshita T, Suzuki T, Shoichiro S, Koike M. Early and follow-up results of butterfly resection of prolapsed posterior leaflet in 76 consecutive patients. J Thorac Cardiovasc Surg. 2015;149:1296-300.

2. Perier P, Stumpf J, Götz C, Lakew F, Schneider A, Clausnizer B, et al. Valve repair for mitral regurgitation caused by isolated prolapse of the posterior leaflet. Ann Thorac Surg. 1997;64:445-50.

3. Sawazaki M, Tomari S, Izawa N, Ueda Y. Hourglass-shaped resection technique for repair of tall mitral valve posterior leaflet prolapse. J Thorac Cardiovasc Surg. 2013;146:275-7

4. Abicht TO, Andrei AC, Kruse J, McDonald E, Li Z, McCarthy PM. A simple approach to mitral valve repair: Posterior leaflet height adjustment using a partial fold of the free edge. J Thorac Cardiovasc Surg. 2014;148:2780-6.

5. Lawrie GM, Earle EA, Earle N. Intermediate-term results of a nonresectiona dynamic repair technique in 662 patients with mitral valve prolapse and mitral regurgitation. J Thorac Cardiovasc Surg. 2011;141:368-76.

\footnotetext{
From the Duke University Medical Center, Durham, NC.

Disclosures: Author has nothing to disclose with regard to commercial support.

Received for publication Jan 28, 2015; accepted for publication Jan 28, 2015; available ahead of print March 6, 2015.

Address for reprints: Donald D. Glower, MD, Duke University Medical Center,

Box 3851, Durham, NC 27710 (E-mail: d.glower@duke.edu).

J Thorac Cardiovasc Surg 2015;149:1301

$0022-5223 / \$ 36.00$

Copyright (c) 2015 by The American Association for Thoracic Surgery

http://dx.doi.org/10.1016/j.jtcvs.2015.01.050
} 